\title{
Esgrima na educação física escolar: uma forma de inclusão social
}

\section{Fencing in school physical education: a form of social inclusion}

\author{
DOI:10.34117/bjdv5n12-058
}

Recebimento dos originais: 07/11/2019

Aceitação para publicação: 05/12/2019

\author{
Thiago Savio Ingles da Luz \\ Instituição: Universidade Estadual de Ponta Grossa \\ Endereço: Rua Bôrtolo Nadal, 147- Uvaranas, Ponta Grossa-PR, Brasil. \\ E-mail:inglesthiago@ hotmail.com \\ Gonçalo Cassins Moreira do Carmo \\ Instituição: Universidade Estadual de Ponta Grossa \\ Endereço: Rua Campos Vergueiro, 459- Uvaranas, Ponta Grossa-PR, Brasil. \\ E-mail: goncalocassins@gmail.com \\ Luan Giovani Gelber \\ Instituição: Universidade Estadual de Ponta Grossa \\ Endereço: Rua Marquês do Paraná, 495- Ronda, Ponta Grossa-PR, Brasil. \\ E-mail: luangelber98@gmail.com \\ Jussiara Lichacovski \\ Instituição: Colégio Estadual Prof. Becker e Silva \\ Endereço: Rua Conrado Schiffer, 80 (AP 604) - Oficinas, Ponta Grossa-PR, Brasil. \\ E-mail: jussi25@gmail.com
}

\section{RESUMO}

Este estudo apresenta a forma com que o conteúdo luta foi desenvolvido na Educação Física, em especial, a esgrima, modalidade pouco desenvolvida nas instituições de educação básica. Para isso, os bolsistas do Programa Institucional de Bolsas de Iniciação à Docência (PIBID - Educação Física) auxiliaram nas etapas do ensino da esgrima, a saber: uma aula expositiva sobre a modalidade, outra para confecção dos equipamentos com a utilização de materiais recicláveis e por último, a sua prática. Além disso, buscou-se a inclusão de dois alunos com deficiência, que tinham dificuldades na realização de práticas de aulas tradicionais como futsal, basquete, vôlei e handebol. Os resultados obtidos foram positivos pois observou-se a participação satisfatória e integral dos alunos.

Palavras chave: esgrima, inclusão social, PIBID, Educação Física.

\begin{abstract}
This study presents the way the content fight was developed in Physical Education, especially fencing, a modality little developed in institutions of basic education. To this end, the scholarship holders of the Institutional Teaching Initiation Scholarship Program (PIBID - Physical Education) assisted in the stages of fencing teaching, namely: one lecture on the modality, another to make equipment using recyclable materials and Finally, your practice. In addition, we sought to include two students with disabilities, who had difficulties in performing traditional classroom practices such as futsal, basketball, volleyball and handball. The results obtained were positive because it was observed the satisfactory and integral participation of the students.
\end{abstract}

Keywords: fencing, social inclusion, PIBID, Physical Education. 


\section{INTRODUÇÃO}

\section{Nome Do Programa Ou Projeto}

- Programa Institucional de Bolsas de Iniciação à Docência (PIBID).

\section{Público-Alvo}

- Alunos dos oitavos e nonos anos do Colégio Estadual Becker e Silva.

\section{Municípios Atingidos}

- Ponta Grossa (PR).

\section{Local De Execução}

- Colégio Estadual Becker e Silva.

\section{JUSTIFICATIVA}

As graduações de licenciatura objetivam a formação de professores, porém a vivência intraescolar nos anos iniciais de formação é pequena, o que dificulta a relação entre teorias e práticas de ensino. Diante disso, o Projeto Institucional de Bolsas de Iniciação à Docência (PIBID) proporciona experiências na escola a acadêmicos dos cursos de licenciatura que permitem estreitar essa relação. Dessa forma, a presente produção obtém relevância pois diz respeito a atividades desenvolvidas e/ou auxiliadas por acadêmicos do primeiro e segundo ano do curso de licenciatura em Educação Física, ou seja, que estão no estágio inicial de formação, o que agrega experiências relevantes a sua formação profissional.

\section{OBJETIVOS}

Apresentar a luta como um conteúdo da Educação Física no ensino básico e promover a prática da esgrima. Promover a inclusão de alunos com deficiência (um autista e um com paralisia cerebral) nas aulas práticas.

\section{METODOLOGIA}

Inicialmente, utilizou-se de uma aula expositiva, teórica, sobre a esgrima no âmbito histórico, de suas regras e materiais para a prática. Na aula seguinte, os alunos levaram de suas casas os materiais recicláveis necessários para confeccionar os equipamentos, sendo a espada e o colete, por fim, promoveu-se a prática.

\section{RESULTADOS}

A Luta é conteúdo estruturante da Educação Física na educação básica nas séries analisadas (oitavo e nono ano), como sugere a Base Nacional Comum Curricular (BNCC), juntamente com 
esportes, danças, ginásticas e práticas corporais de aventura. Nascimento e Almeida (2007) afirma que a luta como tema/conteúdo, em alguns casos, desvincula-se da Educação Física e projeto políticopedagógico da escola e quando trabalhado, segundo Nascimento (2005), ocorre em oficinas através da abertura da instituição para terceiros realizarem. Diante disso, notou-se a necessidade de abordar o conteúdo lutas, mais precisamente, a esgrima. A esgrima é um combate qual utiliza-se de arma branca para atacar e defender, quando a espada toca o colete do adversário, marca-se o ponto. Os materiais necessários para a prática podem ser vistos como um empecilho para o seu desenvolvimento na educação básica. Para tanto, utilizou-se de materiais recicláveis para confeccionar as ferramentas necessárias: jornal e fita para a espada e papelão para fazer o colete, além de tinta a base de água que era colocada na ponta da espada para marcar o colete adversário e dessa forma facilitar a marcação dos pontos e ainda, confeccionou-se a pista (espaço onde a prática ocorre) no pátio da instituição, demarcando-a com fita crepe. Além disso, obteve-se êxito na inclusão de dois alunos deficientes nas aulas práticas, diferente das modalidades tradicionais como basquete, vôlei, futsal, handebol e queimada. Campos e Araújo (2018) tratam como um fato a segregação de pessoas com deficiência em nossa sociedade, o que ocorre durante as práticas de esportes tradicionais, diferente do que ocorreu no desenvolvimento da esgrima. Todos os alunos, demonstraram grande interesse na aula, inclusive os que apresentavam deficiência, por se tratar de uma modalidade que não conheciam, não haviam estudado e nem executado.

\section{FOTO}

Figura 1 - Esgrima e inclusão

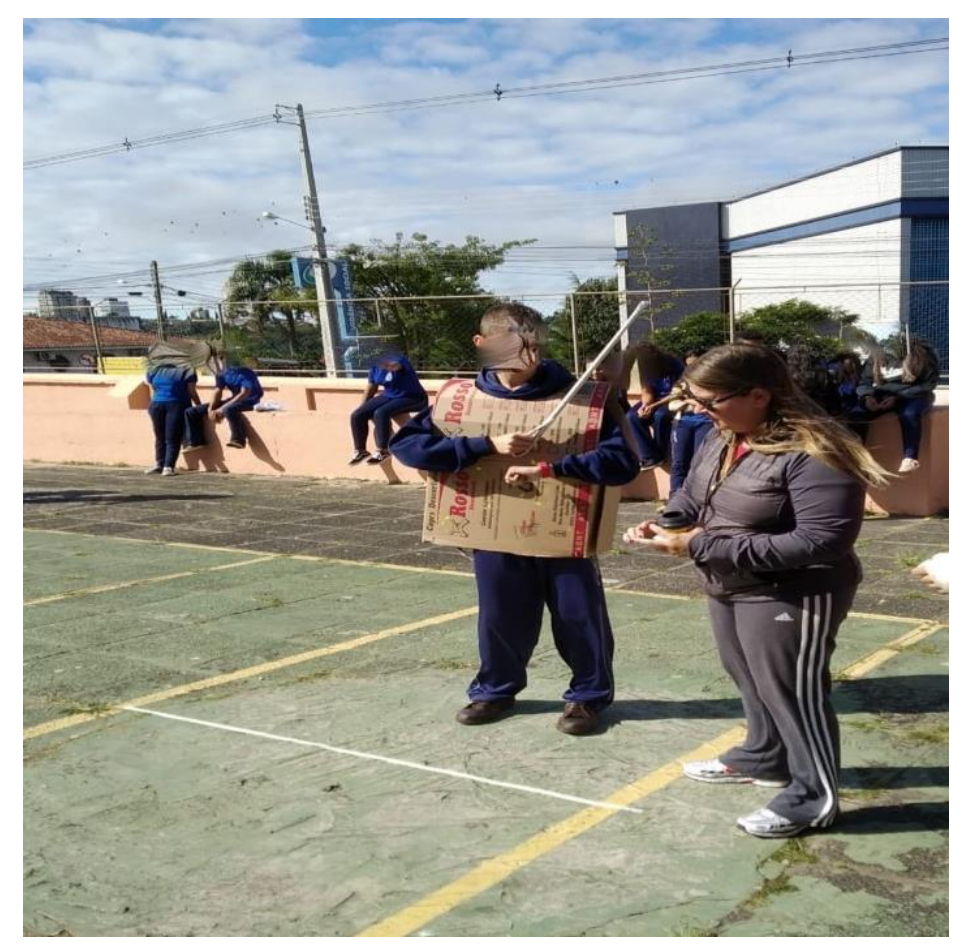

Aluno do $9^{\circ}$ ano com paralisia cerebral infantil incluído na prática da esgrima. 


\section{Brazilian Hournal of Development}

\section{CONSIDERAÇÕES FINAIS}

A presente produção objetivou apresentar e promover a prática da esgrima, uma luta que como outras é pouco trabalhada no âmbito escolar. Diante disso, buscou-se promover a inclusão nas aulas práticas de dois alunos da instituição que são deficientes e que possuem dificuldades para participar das práticas de modalidades tradicionais, por limitação física ou por discriminação dos demais participantes. Obteve-se resultados positivos já que os demais colegas se empenhavam para que os alunos deficientes conseguissem realizar uma prática satisfatória, marcando pontos e vencendo combates.

O presente estudo se faz importante na vivência intraescolar no desenvolvimento de conteúdos poucos trabalhados e que podem servir como ferramenta inclusiva para alunos com deficiência, levando-se em consideração o perfil de cada turma. Destaca-se a necessidade de mais estudos a serem desenvolvidos na área para aprofundar as reflexões inclusivas ou na elaboração de diferentes maneiras de trabalhar conteúdos que pertencem à Educação Física, mas acabam não sendo por ela contemplados na educação básica, buscando assim a maior valorização e sistematização dela como área do conhecimento.

\section{REFERÊNCIAS}

CAMPOS, R. C. P. R. de.; ARAÚJO, N. R. de. Situação educacional de crianças e jovens com deficiência em acolhimento institucional. Caderno de pesquisa, São Paulo, v.48, n. 170, p. 11481166, dez. 2018.

NASCIMENTO, P. R. B. A capoeira no contexto da escola e da Educação Física. 2005, Dissertação (Mestrado) - Faculdade de Pedagogia, Universidade Regional do Noroeste do Estado do Rio Grande do Sul, UNIJUÍ, Ijuí, 2005.

NASCIMENTO, P. R. B.; ALMEIDA, L. de. A tematização das lutas na Educação Física Escolar: restrições e possibilidades. Revista Movimento, Porto Alegre, v. 13, n. 3, p. 91-110, set./dez. 2007.

BASE nacional comum curricular. Disponível em:< http://basenacionalcomum.mec.gov.br/images/BNCC_EI_EF_110518_versaofinal_site.pdf>. Acesso em: 09 jul. 2019. 